\title{
Genotoxicity of an Inorganic Pesticide, Copper Sulphate in Mouse in vivo Test System
}

\author{
S. P. Bhunya and P. C. Pati \\ Laboratory of Genetic Toxicology, P. G. Department of Zoology, \\ Utkal University, Vani Vihar, Bhubaneswar-751 004, India
}

Accepted December 11, 1986

Even after the invasion of a pretty good number of organic pesticides, a number of inorganic pesticides are still widely used in many countries including India. Clastogenicity of a number of inorganic pesticides has been studied in various test systems (Epstein and Legator 1971, Rozynkowa and Raczkiewicz 1977, Kanematsu et al. 1980, Rossman et al. 1980, Sugimura et al. 1982, Bhunya et al. 1982). Copper sulphate, a broad spectrum inorganic pesticide, has manyfold use as fungicide, molluscicide and weedicide and has been reported to be mutagenic in $E$. coli and S. typhimurium (Ishizawa et al. 1978, Hansen and Stern 1984), to cause no DNA damage in prokaryotes (Matsui 1980) and to enhance viral transformations (Casto et al. 1979). Information on the genotoxicity of copper sulphate in mammalian test system is lacking very much. So it was thought imperative to assay the genotoxicity of copper sulphate $\left(\mathrm{CuSO}_{4}\right)$ in the cytogenetic test system of mouse.

\section{Materials and methods}

\section{Test animal and chemical}

Inbred Swiss mice (10-12 weeks old), of average body weight $25 \mathrm{~g}$, were used in the present study. Analytical grade of copper sulphate $\left(\mathrm{CuSO}_{4} \cdot 5 \mathrm{H}_{2} \mathrm{O}(\mathrm{BDH})\right)$ served as test chemical. Glass double distilled water was used as vehicle for chemical administration. Animals injected with equivalent amount of g.d.d. water served as controls.

\section{Bone marrow chromosome aberration assay}

Different doses $(5,10$ and $20 \mathrm{mg} / \mathrm{kg} \mathrm{b.w.)} \mathrm{of} \mathrm{the} \mathrm{chemical,} \mathrm{different} \mathrm{routes} \mathrm{(i.p.,} \mathrm{or} \mathrm{and} \mathrm{sc)} \mathrm{of}$ administration and different exposure times $(6,24$ and 48 hours) were employed for acute treatment. For chronic treatment, the highest dose $(20 \mathrm{mg} / \mathrm{kg})$ was divided into 5 equal parts and each part was injected (i.p.) repeatedly 5 times with a gap of 24 hours inbetween the treatments and animals were sacrificed 24 hours after the last injection. Cytological slides were prepared following usual colchicine air-drying Giemsa schedule and 100 good metaphase spreads were scored per animal.

\section{Sperm abnormality assay}

Each dose was fractionated into five equal parts and each part was injected (i.p.) repeatedly five times with an interval of 24 hours inbetween the treatments and animals were sacrificed 35 days after the first injection (Wyrobek and Bruce 1975). Sperm smears were done after its collection from caudae epididymides in isotonic saline and $10 \%$ Giemsa (BDH) was used for staining. Per animal 500 sperms were examined and sperm abnormalities were categorised, wherever possible, according to Wyrobek and Bruce (1975). 


\section{Micronucleus assay $(M N)$}

For MN assay each dose was injected (i.p.) twice at an interval of 24 hours and the animals were sacrificed 6 hours after the 2nd injection. Smear of bone marrow cells and staining were done following Schmid (1976) with modification (Das and Kar 1980). One thousand each of polychromatic erythrocytes (PCEs), normochromatic erythrocytes (NCEs) and immature white cells were scored per animal.

For all sorts of treated series parallel controls have been done. An equality of proportion test has been used for statistical analysis of the results. The value is considered to be significant when $\mathrm{Z} \geq 1.96$.

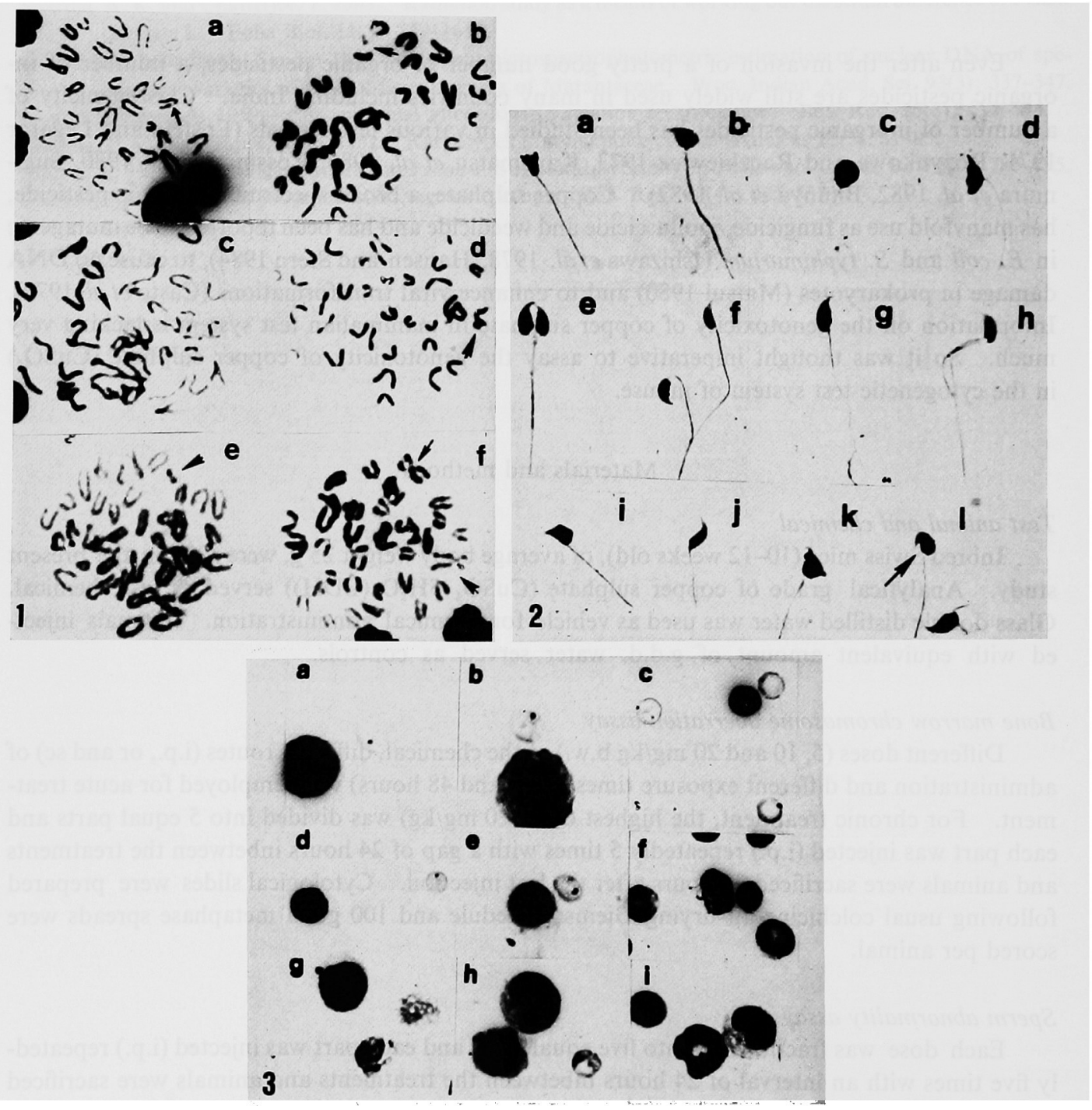

Figs. 1-3. 1, bone marrow chromosome aberrations. (a) chromatid gap, (b)-(c) chromatid breaks, (d) fragment, (e) double minutes and (f) exchanges. 2, photomicrograph showing sperm abnormalities. (a) calyx type, (b) amorphous, (c) balloon type, (d) sunflower type, (e) double headed, (f) branched type, (g) distally branched type, (h) double tailed, (i) rhomboid type, (j) banana type, (k) funnel type and (1) beak type acrosomal end. 3, photomicrograph showing micronuclei and nuclear lysis. (a)-(b)-(c) PCEs with MN, (d)-(e) NCEs with MN, (f) nuclear lysis and (g)(h)-(i) immature nucleated cells with $\mathrm{MN}$. 


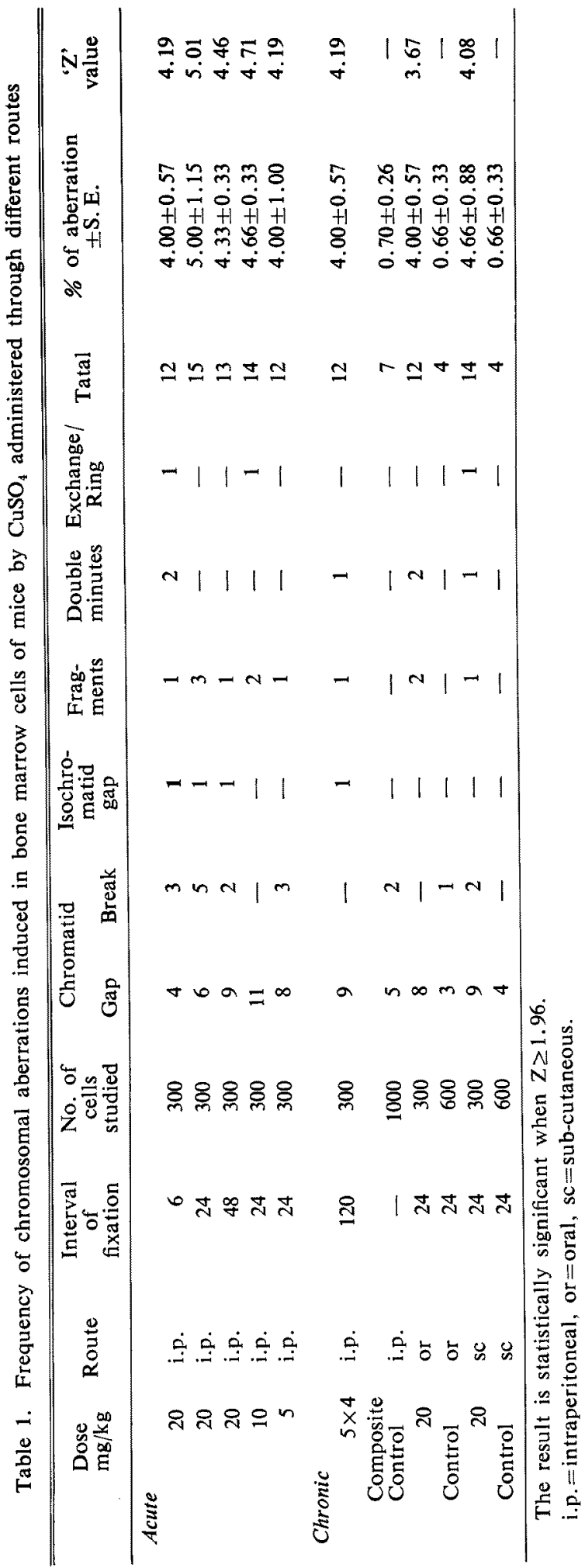




\section{Results}

The treatment of the chemical induced some general physiological effects like corrosiveness and chromatin and centromeric stretching. The chemical also induced aberrations like chromatid and isochromatid gaps, chromatid breaks, fragments, double minutes, exchanges and rings (Fig. 1). Gaps were more frequent than breaks. A tentative assessment revealed that distal regions and long chromosomes were more vulnerable to the chemical. The results were dose, time and route dependent (Table 1). Repeated exposure (chronic) of fractionated doses induced less aberration than that of equivalent dose treated once.

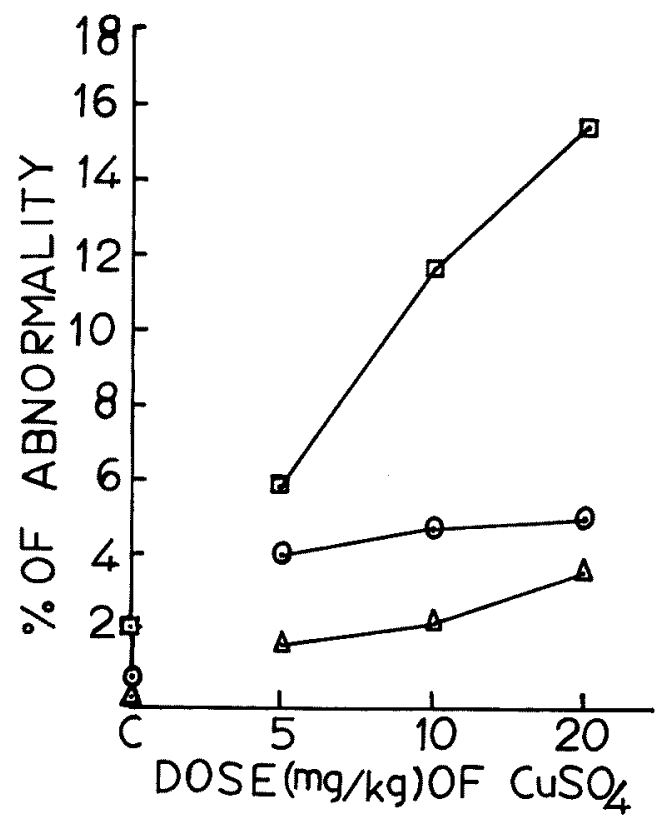

Fig. 4, Dose response relationship for the yield of $\mathrm{MN}(\triangle)$, bone marrow chromosome aberration $(O)$ and sperm abnormality $(\square)$ in mouse, C in abscissa indicates control.

Table 2. Incidence of sperm abnormality in mice by $\mathrm{CuSO}_{4}$ treated i.p.

\begin{tabular}{ccccc}
\hline Dose $\mathrm{mg} / \mathrm{kg}$ & $\begin{array}{c}\text { No. of animals/ } \\
\text { no. of sperm } \\
\text { studied }\end{array}$ & $\begin{array}{c}\text { No. of abnormal } \\
\text { sperms }\end{array}$ & Mean \% $\%$ S.E. & ' $Z$ ' value \\
\hline 20 & $3 / 1500$ & 231 & $15.40 \pm 0.81$ & 17.09 \\
10 & $3 / 1500$ & 166 & $11.60 \pm 0.98$ & 12.97 \\
5 & $3 / 1500$ & 87 & $5.80 \pm 1.41$ & 6.59 \\
Control & $3 / 3000$ & 62 & $2.06 \pm 0.54$ & - \\
\hline
\end{tabular}

The result is statistically significant when $\mathrm{Z} \geq 1.96$.

Varieties of sperm abnormalities were also induced by the chemical. Varied head shape, different modes of tail attachments, double headed and double tailed sperms have been recorded (Fig. 2). The frequency of sperm abnormality was dose dependent (Table 2).

Dose dependent increase in the incidence of micronuclei in bone marrow cells has been observed (Table 3). Some cases of nuclear lysis have also been recorded. Of the three cell types, highest percentage of micronuclei has been recorded in PCEs and least in immature white 


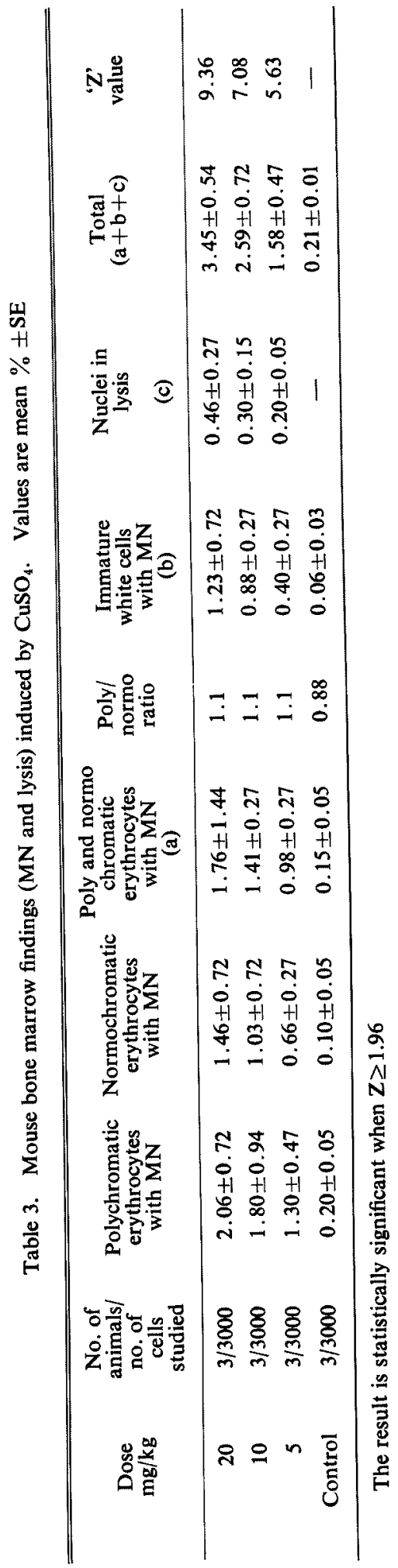


cells. The micronuclei were either dot or ring shaped (Fig. 3) and size varied from $1 / 7$ to $1 / 12$ of the cell size.

All the treated results differed significantly from the controls (Tables 1-3) and relative sensitivity of three assays has been found to be: sperm abnormality $>$ chromosome aberration $>$ micronuclei (Fig. 4).

\section{Discussion}

Rosen (1964) reported strong chromosome breaking capacity of copper in plants. In the present study, copper sulphate also has induced varieties of bone marrow chromosome aberrations in mice.

The results revealed the dose dependent chromosome abrerrations (Table 1). Increased frequency of aberration with higher dose is due to the fact that higher dose facilitates better availability of the chemical in the target tissue or cells (Matter 1976, Behera and Bhunya 1980, Bhunya and Behera 1984). Decrease of aberration frequency in late hours indicates that probably it is due to the elimination of reactive metabolites from the body with time and elimination of major portion of potential damage after one cell cycle time (Schmid 1973).

As regards route sensitivity, highest effect was produced by the chemical administered i.p. and least orally. Copper is known to be absorbed with difficulty in minute quantities from mucous surfaces (Sengupta 1976) and which might be the plausible reason for the least effect in oral route.

The chemical did not shown cumulative effect since repeated fractionated dosing produced less aberration than the equivalent acute dose. Probably due to the fractionated dosing critical concentration of the metabolites for mutagenic events was not sufficient in the target cells (Matter 1976, Behera and Bhunya 1980). Regarding regional and group-wise chromosomal sensitivity to aberrations, it is envisaged that non-random distribution of gaps and breaks in the distal regions and on larger chromosomes might be due to specific molecular make up of particular chromosome part (Hsu and Somers 1961, Manna and Das 1973).

In the present invesigation induction of double minutes (DMs) by copper sulphate is somewhat interesting and important. Till date DMs have been reported mostly in neoplastic cells (Levan et al. 1976, 1978, Mitra et al. 1983, Gebhart et al. 1984). But possibilities of generation of DMs in normal cells cannot be ignored. Contradictory views have been proposed regarding the generation of DMs. It has also been pointed out that some small acentric fragments induced by mutagen could be misinterpreted as DMs (Arrighi 1983, Bullerdiek et al. 1983). Others even argued that DMs found in neoplastic cells might be a consequence of chromosome damage following cytostatic therapy (Weh et al. 1982). However, misinterpretation of randomly stained fragments as DMs can easily be overcome by the specific staining pattern of DMs (Barker and Hsu 1978). Recentrly Mitra et al. (1983) have reported DMs in leucocytes of human with previous history of cervical carcinoma and have opined that some possible common agent(s) is responsible for the production of DMs in tumor cells as well as in normal cells. Also from the present results it is envisaged (with some reservation) that DMs, like other aberrations, can be induced by some mutagens in normal cells. However, nothing can be said rigidly at this juncture and we shall have to wait for more data, to generalise the view.

Regarding mechanism of actions of $\mathrm{CuSO}_{4}$ at chromsomal level, it has been reported (Sengupta 1976) that soluble salts of copper precipitates protein and acts as an antringent. Occurrence of corrosiveness and chromatin stretching in the present case indicates that the chemical acted upon the protein moiety of the chromosomes. DNA damaging inability in prokaryotes (Matsui 1980) and induction of increased error in cell free DNA synthesis 
(Flessel et al. 1980) by Cu are known. The binding of the metallic salts to the nucleic acid resulting in irreversible conformational changes of chromosomes has been reported by Sharma (1984). Similar causes are attributed to the present case for induction of gaps and breaks. Induction of sperm abnormality by any agent is of great cytogenetic significance (Soares et al. 1979). Certain specific kinds of sperm abnormality induced by radiation have been shown to be heritable (Hugenholtz and Bruce 1977). In the present case higher incidence of sperm abnormalities induced by copper sulphate may be a measure of the genetic damage caused in the germline cells.

MN test is comparable to, or even more sensitive and reliable than metaphase scoring for chromosomal aberrations (Schmid 1976). Higher incidence of micronuclei in the treated series definitely indicates the clastogenic effect of $\mathrm{CuSO}_{4}$ in mouse.

The results of the present investigation clearly reveal the genotoxic property of copper sulphate in mouse in vivo test system. Further work especially in human test system and restricted use of copper sulphate are suggested.

\section{Summary}

Mutagenicity of copper sulphate was evaluated in vivo by chromosome aberration, sperm abnormality and micronucleus tests in mice. Dose, route and time influenced significantly the frequency of chromosome aberration, incidence of micronucleus and sperm abnormality. Relative sensitivity of three assays are: sperm abnormality $>$ chromosome aberration $>$ micronuclei formation. The present results revealed the mutagenic property o $\mathrm{CuSO}_{4}$ in mouse in vivo test system.

\section{Acknowledgements}

Authors are thankful to Prof. (Mrs.) P. Mohanty-Hejmadi, Head of the Department of Zoology for providing facilities and to the Department of Education, Government of Orissa for sanctioning study leave to PCP. Thanks are also due to Messrs M. K. Mohanty, B. C. Behera and R. C. Baliarsingh for help.

\section{References}

Arrighi, F. E. 1983. Gene amplification in human tumor cells. In: 13th Int. Cancer Congr., Part C: Biology of Cancer (2): 259-268, A. R. Liss, NY.

Barker, P. E. and Hsu, T. C. 1978. Are double minutes chromosomes? Exp. Cell Res. 113: 456-458.

Behera, J. and Bhunya, S. P. 1980. In vivo effects of a commercial herbicide, Amiben on bone marrow and germ cells of mice. Caryologia 33 : 527-535.

Bhunya, S. P. and Behera, J. 1984. Clastogenicity of a fungicide, Ediphenphos (Hinosan) in the bone marrow cells of mice in vivo. Cytologia 49: 833-839.

-, Samal, T. and Behera, J. 1982, Relative sensitivity of mammalian and insect chromosomes to Borax and Weedazol-TL. Proc. Sem. Effect of environmental agents on genetical system: 13.

Bullerdiek, J., Bartnitzke, S. and Schloot, W. 1983. Cells with double minutes divided into two categories. Cancer Genet. Cytogenet. 9: 303-304.

Casto, B. C., Meyers, J. and Dipaolo, J. A. 1979. Enhancement of viral transformation for evaluation of the carcinogenic or mutagenic potential of inorganic metal salts, Cancer Res. 39: 193-198.

Das, R. K. and Kar. R. N. 1980. Sodium citrate solution as a substitute for fetal calf serum in micronucleus preparation. Stain Technol. 55: 43.

Epstein, S. S. and Legator, M. S. 1971. The Mutagenicity of Pesticides Concepts and Evaluation. The MIT Press, Cambridge, Massachusetts and London, England.

Flessel, C. P., Furst, A. and Radding, S. B. 1980. In: Metal ions in biological systems 10: 23.

Gebhart, E., Bruderlein, S., Tulusan, A. H., Maillot, K. V. and Birkmann, J. 1984. Incidence of double minutes, 
cytogenetic equivalents of gene amplification, in human carcinoma cells. Int. J. Cancer 34: 369-373.

Hansen, K. and Stern, R. M. 1984. A survey of metal induced mutagenicity in vitro and in vivo, J. Amer. Col. Tox. 3: $381-430$.

Hsu, T. C. and Somers, C. E. 1961. Effect of 5-bromodeoxyuridine on mammalian chromosomes. Proc. Natl. Acad. Sci. (Wash.), 47: 396-403.

Hugenholtz, A. P. and Bruce, W. R. 1977. Transmission of radiation-induced elevations in abnormally shaped murine sperm. In: Abstracts of the 8th Annual Meeting of the Enviromental Mutagen Society, Denver, Colorado p. 75 .

Ishizawa, M., Endo, T. and Endo, H. 1978. Cretine and creatinine are mutagenic when nitrosated under gastric conditions after heating with copper ion. Mutation Res. 54: 214.

Kanematsu, N., Hara, M. and Kada, T. 1980. Rec. assay and mutagenicity studies on metal compounds. Mutation Res. 77: 109-116.

Levan, A., Levan, G. and Mandahl, N. 1978. A new chromosome type replacing the double minutes in a mouse tumor. Cytogenet. Cell Genet, 20: 12-23.

Levan, G., Mandahi, N., Bregula, U., Klein, G. and Levan, A. 1976. Double minute chromosomes are not centromeric regions of the host chromosomes. Heriditas 83: 83-90.

Manna, G. K. and Das, P. K. 1973. Effect of two chemosterilants Apholate and Hempa on the bone marrow chromosomes of mice. Can. J. Genet. Cytol. 15: 451-459.

Matsui, S. 1980. Evaluation of a Bacillus subtilis rec. assay for the detection of mutagens which may occur in aquatic environment. Water Res. 14: 613-619.

Matter, B. E. 1976. Problems of testing drugs for potential mutagenicity. Mutation Res. 38: $243-258$.

Mitra, A. B., Murty, V. V. V. S. and Luthra, U. K. 1983. Double minute chromosomes in the leucocytes of a patient with a previous history of cervical carcinoma. Cancer Genet. and Cytogenet. 8: 117-122.

Rosen, G. 1964. Mutations induced by the action of metal ions in Pisum II. Heriditas 51. 1: 90

Rossman, T. G., Stone, D., Molina, M. and Troll, W. 1980. Absence of arsenite mutagenicity in $E$. coli and Chinese hamster cells. Environ. Mutagen. 2: 371-379.

Rozynkowa, D. and Raczkiewicz, B. 1977. Destructive effect of methylmercury chloride on human mitosis in living cells in vitro. Mutation Res. 56: 185-191.

Schmid, W. 1973. Chemical mutagen testing on in vivo somatic mammalian cell. Agents and Actions 3: $77-85$.

- 1976. The micronucleus test. In: Chemical Mutagens; Principles and Methods for their Detection, Vol. 4, A. Hollaender ed: (Plenum Press, NY) P 31.

Sengupta, S. S. 1976. Pharmacology Materia Medica and Therapeutics. Hilton Co. Calcutta.

Sharma, A. 1984. Genetical effects of metallic salts on eukaryotic system, Persp. Cyto. Gen. 4: 21-24.

Soares, E. R., Sheridan, W., Haseman, J. K. and Segall, M. 1979. Increased frequencies of aberrant sperm as indicators of mutagenic damage in mice, Mutation Res. 64: 27-35.

Sugimura, T., Kondo, S. and Takebe, H. 1982. Environmental Mutagens and Carcinogens. University of Tokyo Press, Tokyo; Alan R. Liss, Inc., NY.

Weh, H. J., Zschaber, R. and Hossfeld, D. K. 1982. Double minute chromosomes : a frequent marker in leukemic patients with a previous history of malignant disease. Cancer Genet. and Cytogenet, 5: 279-280.

Wyrobek, A. J. and Bruce, W. R. 1975, Chemical induction of sperm abnormality in mice. Proc. Natl. Acad. Sc. USA. 72: $4425-4429$. 